\title{
Fetal Pulmonary Artery Acceleration/Ejection Time Prognostic Accuracy for Respiratoy Complications in Preterm Prelabor Rupture of Membranes
}

Mohamed Saber Mahrous ${ }^{1, *}$ MSc, Ehab Hasanin Mohammed ${ }^{1}$ MD. and Abd-Elmonsef Abd-Elhamid Sedek ${ }^{1}$ MD.

\section{* Corresponding Author: \\ Mohamed Saber Mahrous \\ Mohamedelsebaey2014@gmail.com}

Received for publication January 03, 2021; Accepted March 18, 2021; Published online March 18, 2021.

Copyright 2020 The Authors published by Al-Azhar University, Faculty of Medicine, Cairo, Egypt. All rights reserved. This an openaccess article distributed under the legal terms, where it is permissible to download and share the work provided it is properly cited. The work cannot be changed in any way or used commercially.

doi: 10.21608 /aimj.2021.56340.1393

${ }^{1}$ Obstetrics and Gynecology Department, Faculty of Medicine, Al-Azhar University Cairo, Egypt.

Disclosure: The authors have no financial interest to declare in relation to the content of this article. The Article Processing Charge was paid for by the authors.

Authorship: All authors have a substantial contribution to the article.

\begin{abstract}
Background: Preterm premature rupture of membranes (PPROM) impacts on approximately 3 percentage of pregnancies and is linked with severe maternal problems, resulting in, significant neonatal mortality and morbidity. The pulmonary artery acceleration to ejection period (PATET) ratio has been revealed

Aim of the work: to predict respiratory complications in late preterm neonates between the various ultrasound factors tested to predict neonatal respiratory complications (NRCs).

Patients and methods: This study was a prospective study performed at Bab El Sheria Al-Azhar University Hospital among 385 pregnant women undergoing prenatal treatment in the Department of Gynecology and Obstetrics. We noticed 36 patients with NRC deemed to be a case group and took 36 patients without NRC as a control group. PATET has been performed. Baseline features and functional perinatal outcomes were taken from the medical records after delivery.

Results: In patients with NRC, the delivery mode was statistically significantly more significant than in patients without NRC. There was a statistically significant decrease in birth weight and gestational age, Apgar scores at 1 and 5-minutes among NRC patients relative to nonNRC patients. In addition, there was a statistically significant reduction of pulmonary artery acceleration in patients with NRC during ejection duration relative to patients without NRC. Statistically significant positive associations were observed between the pulmonary artery's acceleration to the ejection period and gestational age.

Conclusion: The assessment of PATET offers a non-invasive way of assessing neonatal respiratory complications in the preterm prelabor of membranes with reasonably appropriate degrees of specificity, sensitivity, accuracy, and predictive values.
\end{abstract}

Keywords: Fetal; pulmonary artery; respiratory complications; rupture of membranes.

\section{INTRODUCTION}

In around 3-10 percent of all pregnancies, premature membrane rupture (PROM) occurs; it is known as a rupture of the membranes hour before the start of uterine contractions, nevertheless of gestational age. ${ }^{1}$ PROM complicates roughly 2-4 percent of singleton pregnancy and approximately 7-20 percent of multiple pregnancies. For both infants and mothers, this complication is a primary source of elevated mortality and morbidity. ${ }^{2}$

PROM occurs in approximately 30 to 40 percent of all preterm deliveries, which is also a significant concern in perinatal medicine. In addition to prematurity, cancer, sepsis, bleeding, infant distress, intraventricular hemorrhage, and respiratory problems are neonatal complications. ${ }^{3}$ Consequently, a non-invasive screening technique that reliably predicts respiratory problems in PPROM may be used to classify those that could gain from therapies intended to minimize contagious morbidity across gestational ages or maybe previously in pregnancy. ${ }^{4}$ The pulmonary artery ejection period acceleration (PATET) ratio has been revealed to predict respiratory problems in late preterm neonates among the various ultrasound parameters tested for predicting neonatal respiratory complications (NRCs). ${ }^{5}$

The research goal was to evaluate the fetal pulmonary artery expulsion period's predictive accuracy for predicting neonatal respiratory problems in pregnancies of early rupture of premature membranes.

\section{PATIENTS AND METHODS}

This research was a prospective study carried out during the duration from November 2019 to June 2020 among 385 pregnant women attending prenatal care at the Department of Gynecology and Obstetrics at Bab El Sheria Al-Azhar University Hospital. All women solicited for enrollment and provided written informed consent.

Inclusion criteria: Pregnant mothers of (18-40) years of age. Pregnant mothers are complicated with 
PPROM. Gestational age for a PATET was measured at (28 and36) weeks, surrounded by seven days of delivery.

Exclusion criteria: Pregnancies with multiple gestations. Fetal defects that induce respiratory insufficiency. Clinical data collection: PPROM was diagnosed due to the following criteria: A) rupture of the membranes, B) leaked amniotic fluid, C) singleton pregnancies between 28 and $36+6$ weeks of gestation.

After registration, PATET was done weekly, and the measurements of the week previous delivery were used. Baseline attributes and related perinatal findings were collected following delivery from the medical reports. PATET formula.

PATET $=\frac{\text { Acceleration time }}{\text { Ejection time }}$

Patient preparation: History taking: Detailed obstetric and gynecologic history was taken from these patients. Examination: The general, abdominal, and obstetric examination was done in these patients. The gestational age was analyzed using the date of the last menstrual period and then proved by early ultrasonography of the fetus before considering pregnancy termination. A routine and special investigation were done as: ABO-Rh, CBC, Fasting and post prandial blood glucose level assay, Urine analysis for any disorders as albumin and pus cell and hematuria, Basic ultrasound (abdominal and vaginal). Doppler examination of the fetal pulmonary artery Voluson E6. Probes (C1-5 D, RAB6 - D, IC5 - 9 D, and RIC 5 - 9 D).

Ethical consideration: The Faculty of Medicine's ethics committee - AL Azhar University, submitted the study protocol for approval. Both participants in the study provided informed verbal consent before sharing in the study. Confidentiality and privacy is appreciated in this report.

Statistical analysis: The collected data were tabulated and analyzed, applying SPSS version 16 software (Spss Inc, Chicago, ILL Company). Numbers and percentages were viewed as categorical data. Categorical variables were evaluated using the Chi-square test (X2). Using the Kolmogorov Smirnov test, the quantitative data were checked for normality, assuming normality at $\mathrm{P}>0.05$. A mean \pm standard deviation was reflected in the quantitative results. The " $t$ " student exam was used to evaluate factors usually spread between two different groups. To test the association between non-parametric variables, the correlation coefficient of Pearson was used. The ROC curve was used with optimal precision and precision for the measurement of cutoff values.

\section{RESULTS}

There was no significant statistical discrepancy among patients with NRC and patients without NRC regarding maternal age, BMI, gravidity, and parity. There was a significant statistical variation between patients with NRC and patients without NRC concerning the Mode of delivery (Table 1).

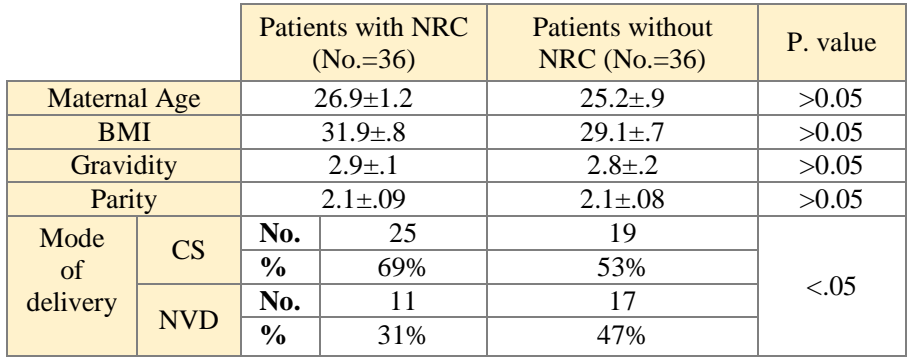

Table 1: Comparison between patients with NRC and patients without NRC concerning Maternal Constitutional Data.

Table (2) shows no significant statistical variation between patients with NRC and patients without NRC concerning Antenatal steroid, gestational diabetes, and chronic hypertension.

\begin{tabular}{|c|c|c|c|c|c|}
\hline & & & $\begin{array}{l}\text { Patients } \\
\text { with } \\
\text { NRC } \\
\text { (No.=36) }\end{array}$ & $\begin{array}{c}\text { Patients } \\
\text { without NRC } \\
(\text { No. }=36)\end{array}$ & $\begin{array}{c}\mathrm{P} \\
\text { value }\end{array}$ \\
\hline \multirow{4}{*}{$\begin{array}{c}\text { Gestational } \\
\text { diabetes }\end{array}$} & \multirow[b]{2}{*}{ Yes } & No. & 4 & 1 & \multirow{4}{*}{$>05$} \\
\hline & & $\%$ & $11 \%$ & $3 \%$ & \\
\hline & \multirow{2}{*}{ No } & No. & 32 & 35 & \\
\hline & & $\%$ & $89 \%$ & $97 \%$ & \\
\hline \multirow{4}{*}{$\begin{array}{l}\text { Antenatal } \\
\text { steroid }\end{array}$} & \multirow{2}{*}{ Yes } & No. & 28 & 30 & \multirow{4}{*}{$>05$} \\
\hline & & $\%$ & $78 \%$ & $83 \%$ & \\
\hline & \multirow{2}{*}{ No } & No. & 8 & 6 & \\
\hline & & $\%$ & $22 \%$ & $17 \%$ & \\
\hline \multirow{4}{*}{$\begin{array}{c}\text { Chronic } \\
\text { hypertension }\end{array}$} & \multirow[b]{2}{*}{ Yes } & No. & 4 & 5 & \multirow{4}{*}{$>05$} \\
\hline & & $\%$ & $11 \%$ & $14 \%$ & \\
\hline & \multirow{2}{*}{ No } & No. & 32 & 31 & \\
\hline & & $\%$ & $89 \%$ & $86 \%$ & \\
\hline
\end{tabular}

Table 2: Comparison between patients with NRC and patients without NRC concerning gestational diabetes, Antenatal steroid, and chronic hypertension.

Table (3) shows a statistically significant decrease in Birth Weight and Gestational age among patients with NRC than patients without NRC. There was a statistically significant decrease in Apgar scores at 1 minute and Apgar scores at 5 minutes among patients with NRC than patients without NRC.

\begin{tabular}{|c|c|c|c|}
\cline { 2 - 4 } \multicolumn{1}{c|}{} & $\begin{array}{c}\text { Patients with } \\
\text { NRC (No.=36) }\end{array}$ & $\begin{array}{c}\text { Patients without } \\
\text { NRC (No.=36) }\end{array}$ & P value \\
\hline Birth weight & $2.3 \pm .2$ & $3.2 \pm .1$ & $<0.05$ \\
\hline $\begin{array}{c}\text { Gestational } \\
\text { age }\end{array}$ & $33.2 \pm 1$ & $35 \pm .2$ & $<0.05$ \\
\hline $\begin{array}{c}\text { Apgar scores } \\
\text { at 1 minute }\end{array}$ & $6.8 \pm .5$ & $8.7 \pm .9$ & $<.05$ \\
\hline $\begin{array}{c}\text { Apgar scores } \\
\text { at 5 minutes }\end{array}$ & $8.2 \pm .4$ & $8.9 \pm .1$ & $<.05$ \\
\hline
\end{tabular}

Table 3: Comparison between patients with NRC and patients without NRC concerning Neonatal Constitutional Data.

Table (4) shows a statistically significant decrease in pulmonary artery hastening to ejection time among patients with NRC than patients without NRC. 


\begin{tabular}{|c|c|c|c|}
\cline { 2 - 4 } \multicolumn{1}{c|}{} & $\begin{array}{c}\text { Patients } \\
\text { with } \\
\text { NRC } \\
\text { (No.=36) }\end{array}$ & $\begin{array}{c}\text { Patients } \\
\text { without } \\
\text { NRC } \\
\text { (No.=36) }\end{array}$ & $\begin{array}{c}\text { P } \\
\text { value }\end{array}$ \\
\hline $\begin{array}{c}\text { pulmonary artery } \\
\text { acceleration to ejection } \\
\text { time }\end{array}$ & $\begin{array}{c}0.2813 \pm \\
0.03\end{array}$ & $\begin{array}{c}0.3991 \pm 0.0 \\
7\end{array}$ & $<.05$ \\
\hline
\end{tabular}

Table 4: Comparison Between patients with NRC and patients without NRC concerning pulmonary artery acceleration to ejection time.

Table (5) revealed statistically significant positive correlations between pulmonary artery acceleration to ejection time and (birth weight, Gestational age, Apgar scores at 1 minute and Apgar scores at 5 minutes). There were no statistically significant correlations between pulmonary artery hastening to ejection time and other variables.

\begin{tabular}{|c|c|c|}
\hline $\begin{array}{c}\text { Pulmonary artery } \\
\text { acceleration to ejection } \\
\text { time }\end{array}$ & \multicolumn{2}{|c|}{$\begin{array}{c}\text { Pearson's } \\
\text { correlation }\end{array}$} \\
\cline { 2 - 3 } & $\mathbf{r}$ & $\mathbf{p}$ \\
\hline Maternal Age & 0.799 & 0.13 \\
\hline BMI & 0.760 & 0.58 \\
\hline Gravidity & 0.054 & .460 \\
\hline Parity & 0.834 & 0.69 \\
\hline Birth weight & 0.8160 & 0.00 \\
\hline Gestational age & 0.708 & 0.00 \\
\hline Apgar scores at 1 minutes & 0.745 & 0.00 \\
\hline Apgar scores at 5 minutes & 0.163 & 0.030 \\
\hline
\end{tabular}

Table 5: Correlation between pulmonary artery acceleration to ejection time and other data.

Table (6) and figure (1) ROC curve of pulmonary artery hastening to ejection time was conducted. Excellent AUC was found (AUC = 0.972). At best cut of the value of pulmonary artery hastening to ejection time (0.30), sensitivity was $96 \%$, specificity was $86 \%$, PPV was $95.6 \%$, NPV was $87.3 \%$, and accuracy was $91 \%$.

\begin{tabular}{|c|c|}
\cline { 2 - 2 } \multicolumn{1}{c|}{} & $\begin{array}{c}\text { pulmonary artery } \\
\text { acceleration to ejection time }\end{array}$ \\
\hline AUC & 0.972 \\
\hline Cut off & 91.5 \\
\hline Sensitivity (\%) & 96 \\
\hline Specificity (\%) & 86 \\
\hline PPV (\%) & 95.6 \\
\hline NPV (\%) & 87.3 \\
\hline Accuracy (\%) & 91.0 \\
\hline
\end{tabular}

AUC; the area under the curve, PPV; positive predictive value, NPV; negative predictive value.

Table 6: Accuracy of pulmonary artery acceleration to ejection time in prediction of NRC.

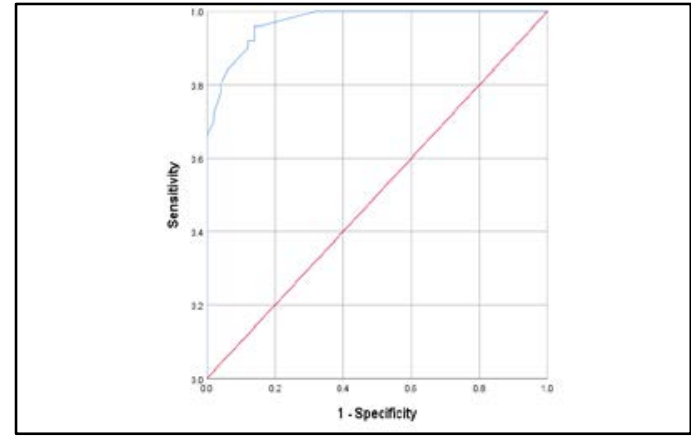

Obstetrics and

Gynecology

Fig. 1: ROC curve for Clinical performance of pulmonary artery hastening to ejection time in prediction of NRC.

\section{DISCUSSION}

The last organs in an embryo to functionally develop are the lungs. The pulmonary vasculature often evolves as the lungs mature during gestation, contributing to reduced pulmonary vascular resistance and improved pulmonary vascular blood flow. In other terms, pulmonary tissue resistance or impedance declines with rising gestational age. In comparison, the pulmonary vasculature, where both the absolute amount of pulmonary arteries increases and the pulmonary arterial vascular resistance reduces significantly, as the lung grows during gestations ${ }^{15}$. High pulmonary tissue resistance can be triggered by some disruption in the lung growth process. Therefore, the incidence of any diseasecausing high pulmonary tissue impedance can be expected if one can calculate pulmonary tissue impedance. Doppler indices for the pulmonary artery may be a means of implicitly assessing pulmonary tissue impedance by calculating arterial resistance. PATET ratio has been a useful non-invasive tool for evaluating flow impedance and pulmonary tissue pressure among the pulmonary Doppler indices. Duncan et al. ${ }^{6}$ By splitting the acceleration period of the fetal primary pulmonary artery Doppler waveform by its ejection time, the PATET value is obtained. $^{9}$ The research goal was to evaluate the predictive accuracy of the fetal pulmonary artery expulsion period hastening for predicting neonatal PPROM.

This research found no significant statistical differences in maternal age, BMI, gravidity, and parity between patients with NRC and patients without NRC. This is following Duncan et al. ${ }^{6}$. Their research was a prospective singleton pregnancy cohort that PPROM controlled in their institution from October 2015 to April 2018. Of the 95 patients involved, 46 were NRC patients. They observed that the baseline profiles of the NRC outcome groups have no demographic differences. My result also agrees with Büke and Akkaya ${ }^{7}$. The goal was to examine whether the ratio of PATET would prophesy or rule out a subsequent diagnosis of transient tachypnea in the infant. No significant statistical variations in maternal obstetric and demographic characteristics were reported between groups. 
This study found a statistically significant difference in delivery mode between patients with NRC and patients without NRC. For patients with NRC, CS was statistically significantly higher than those without NRC. This agrees with NiesłuchowskaHoxha et al. ${ }^{1}$ observed that, in patients with RDS, CS was statistically substantially higher than in patients without RDS. Also, this agrees with Pirjani et al. ${ }^{8}$ observed that CS is linked with a higher rate of neonatal respiratory complications

This research showed no statistically significant difference in gestational diabetes and chronic hypertension between patients with NRC and patients without NRC. This coincides with Duncan et al., ${ }^{6}$ noticed no statistically significant difference in gestational diabetes and Chronic hypertension between patients with NRC and patients without NRC.

This study found a statistically significant decline in birth weight and gestational age for NRC patients relative to non-NRC patients. This correlates with Duncan et al. ${ }^{6}$ observed that birth weight and gestational age were slightly lower among people with NRC.

This study found a statistically significant decrease in the Apgar scores 1 and 5-minute for NRC patients relative to patients without NRC. This is compatible with Niesłuchowska-Hoxha et al. ${ }^{1}$ that there was a statistically significant drop in Apgar scores at 1 minute and Apgar scores at 5 minutes between NRC patients and non-NRC patients.

This research found a statistically significant reduction in pulmonary artery acceleration to the ejection period between NRC patients and non-NRC patient. This agrees with Schenone et al. ${ }^{9}$ before the findings of the amniocentesis were announced, an ultrasound test involving the calculation of PATET was conducted. A lower PATET was observed in a population of amniocentesis indicative of lung immaturity.

This is compatible with Duncan et al. ${ }^{6}$ observed that PATET was lower in NRC patients than those without such complications $(0.22 \pm 0.05$ vs. $0.25 \pm 0.04 ; \mathrm{p} 0.002)$. This also coincides with Büke and Akkaya ${ }^{7}$ observation that the TTN+ group's PATET ratio was slightly smaller than the group of TTN (0.307 vers. $0.389, \mathrm{P}<0.0001)$.

Doppler measures of fetal pulmonary artery started to be published in the late 1980s, and research on the technique's clinical application emerged in the second half of the 1990s. ${ }^{10,11}$

Pulmonary hypoplasia and underlying disorders were first studied concerning the association between PATET ratio and neonatal respiratory problems. ${ }^{12}$ The first study was published in 2010 on the association between PATET ratio and neonatal respiratory failure. The analysis's critical outcome indicator was an association between the rate of lecithin/sphingomyelin (L/S) and the percentage of PATET, which would estimate neonatal discomfort indirectly. There was a negative association between the $\mathrm{L} / \mathrm{S}$ ratio and the fetal PATET ratio.
The likelihood of lung maturity decreased as the PATET ratio and vice versa. ${ }^{13}$ The second study on the topic showed comparable findings to the first report. PATET fetal ratio values were substantially greater in fetuses that eventually formed RDS. ${ }^{14}$

Nevertheless, two subsequent research on the problem showed an opposite association, close to our analysis, between neonatal respiratory distress and PATET ratio. Schenone et al. ${ }^{9}$ explored the association between the PATET ratio and the surfactant/albumin ratio. In another paper, Guan et al. ${ }^{15}$ examined the association between the PATET ratio and the subsequent diagnosis of RDS. They clarified this association based on the proven mechanism of fetal lung maturation; with the evolving fetus, the lungs still expand, pulmonary impedance reductions, pulmonary artery flow rises, and discharge flow peaks throughout mid systole. In comparison, ejection flow peaked earlier in patients with elevated pulmonary impedance.

This study found statistically critical positive associations between the time of ejection and the gestational age of pulmonary artery acceleration. Similarly, Guan et al. ${ }^{15}$ demonstrated that PATET improved with gestational age and obtained reduce PATET in pregnancies confused by RDS. These results agreed with Rasanen et al. ${ }^{16}$ stated that PATET improved with proceeding gestational age. Schenone et al. ${ }^{9}$ discovered a reduced PATET in the group with an amniocentesis population revealing pulmonary immaturity. In addition, Chaoui et al.17 recorded greater PATET values in significant pulmonary branches at higher gestational ages.

This research revealed that the pulmonary artery hastening to ejection time of the ROC curve was performed. An excellent AUC (AUC=0.972) was discovered. Sensitivity was 96 percent, precision was 86 percent, PPV was 95.6 percent, NPV was 87.3 percent, and consistency was 91 percent at the best lower value of pulmonary artery acceleration to ejection time (0.30). This is compatible with Schenone et al. $^{9}$ the ROC curve revealed that a PATET cut-off of 0.3149 given precision of 93 percent (95 percent CI 77-98 percent), a sensitivity of 73 percent (95 percent CI 48-89 percent), a negative predictive value of 87 percent (95 percent CI 70-95 percent), and a positive predictive value of 85 percent (95 percent CI 48-89 percent), and a positive predictive value of 85 percent (95 percent CI 70-95 percent). PATET can provide a noninvasive means of assessing fetal lung maturity with appropriate levels of sensitivity, specificity, and predictive value. This also coincides with Büke and Akkaya $^{7}$ observed 82.7 percent accuracy, 83.3 percent sensitivity, 96 percent negative predictive value, and 41.6 percent positive predictive value given by the cut-off value of 0.319 . This is also compatible with Duncan et al. ${ }^{6}$ considered PATET to be a statistically significant NRC marker in PPROM pregnancy. A statistically important NRC indicator (AUC0.74; 95\% CI:0.61-0.83; p<.001) was the PATET. B€ukeet al.18 recorded an inverse association between RDS diagnosis in neonates and PATET in which 105 births were prospectively monitored, in which 22 formed RDS. When using a 
PATET cut-off of 0.327 , they registered a sensitivity of 90.9 percent and a specificity of 77.1 percent.

\section{CONCLUSION}

The assessment of PATET offers a non-invasive means of assessing neonatal respiratory complications with reasonably appropriate degrees of sensitivity, accuracy, and predictive values in rupture membrane breakup. The ROC curve of pulmonary artery hastening to ejection time was performed. Excellent AUC was observed (AUC = 0.972). Sensitivity was 96 percent, precision was 86 percent, PPV was 95.6 percent, NPV was 87.3 percent, and consistency was 91 percent at the best reduction value of pulmonary artery hastening to ejection period (0.30).

\section{REFERENCES}

1. Niesłuchowska-Hoxha A., Cnota W., Czuba B., et al. A Retrospective Study on the Risk of Respiratory Distress Syndrome in Singleton Pregnancies with Preterm Premature Rupture of Membranes between 24+0 and 36+6 Weeks, Using Regression Analysis for Various Factors. BioMed research international, 2018, 7162478.

2. Liu J., Yang N. and Liu Y. High-risk Factors of Respiratory Distress Syndrome in Term Neonates: A Retrospective Case-control Study. Balkan Medical Journal. 2014;33(1):64-8.

3. van der Ham D. P., Kuijk V. S. and Opmeer B. C. Can neonatal sepsis be predicted in late preterm premature rupture of membranes? Development of a prediction model European Journal of Obstetrics \& Gynecology and Reproductive Biology. 2014;176:90-5.

4. Palacio M, Bonet-Carne E, Cobo T, et al. Prediction of neonatal respiratory morbidity by quantitative ultrasound lung texture analysis: a multicenter study. Am J Obstet Gynecol. 2017;217:196.e1-196.e14.

5. Maged A, Youssef G, Hussien A, et al. The role of three-dimensional ultrasonography fetal lung volume measurement in the prediction of neonatal respiratory function outcome. J Matern Fetal Neonatal Med. 2017;12:1-6.

6. Duncan JR, Tobiasz AM, Dorsett KM, e al. Fetal pulmonary artery acceleration/ejection time prognostic accuracy for respiratory complications in preterm prelabor rupture of membranes. J Matern Fetal Neonatal Med. 2018 Nov 26:1-5.

7. Büke, B. and Akkaya, H. A non-invasive method to rule out transient tachypnea of the newborn (TTN): fetal pulmonary artery acceleration to ejection time ratio. Journal of Perinatal Medicine, 2018; 46(2),

8. Pirjani, R., Afrakhteh, M., Sepidarkish, M. et al. 'Elective caesarean section at 38-39 weeks gestation compared to $>39$ weeks on neonatal outcomes: a prospective cohort study. BMC Pregnancy Childbirth18, 140 (2018).

9. Schenone MH, Samson JE, Jenkins L, et al. Predicting fetal lung maturity using the fetal pulmonary artery Doppler wave acceleration/ejection time ratio. Fetal Diagn Ther. 2014; 36:208-14.

10. Machado M, Chita S and Allan L. Acceleration time in the aorta and pulmonary artery measured by Doppler echocardiography in the midtrimester normal human fetus. Br Heart J. 1987; 58:15-8.

11.Laudy J, Gaillard J, Anker J, et al. Doppler ultrasound imaging: a new technique to detect lung hypoplasia before birth? Ultrasound Obstet Gynecol. 1996;7:189-92.

12. Chaoui R, Kalache K, Tennstedt C, et al. Pulmonary arterial Doppler velocimetry in fetuses with lung hypoplasia. Eur $J$ ObstetGynecolReprod Biol. 1999;84:179-85.

13. Azpurua H, Norwitz ER, Campbell KH, et al. Acceleration/ejection time ratio in the fetal pulmonary artery predicts fetal lung maturity. Am $J$ Obstet Gynecol. 2010 ;203:40.e1-e8.

14. Kim SM, Park JS, Norwitz ER, et al. Acceleration timeto- ejection time ratio in fetal pulmonary artery predicts the development of neonatal respiratory distress syndrome: a prospective cohort study. Amer J Perinatol. 2013;30:805-12.

15. Guan Y, Li S, Luo G, et al. The role of Doppler waveforms in the fetal main pulmonary artery in the prediction of neonatal respiratory distress syndrome. J Clin Ultrasound. 2015; 43:375-83.

16. Rasanen J, Huhta JC, Weiner S, et al. Fetal branch pulmonary arterial vascular impedance during the second half of pregnancy. Am J Obstet Gynecol. 1996; 174:1441-9.

17. Chaoui R, Taddei F, Rizzo G, et al. Doppler echocardiography of the main stems of the pulmonary arteries in the normal human fetus. Ultrasound Obstet Gynecol. 1998;11:173-9.

18. B€uke B, Desteg€ul E, Akkaya H, et al. Prediction of neonatal respiratory distress syndrome via pulmonary artery Doppler examination. J Matern Fetal Neonatal Med. 2017;17:1-6. 